\title{
STREET LAMPS AGGREGATION ANALYSIS THROUGH IEC 61000-3-6 APPROACH
}

\author{
Aurora GIL-DE-CASTRO \\ University of Cordoba - Spain \\ agil@uco.es
}

\author{
Math BOLLEN \\ Lulea University of Technology - Sweden \\ math.bollen@ltu.se
}

\author{
Antonio MORENO-MUÑOZ \\ University of Cordoba - Spain \\ amoreno@uco.es
}

\begin{abstract}
The use of high-power LEDs for street lighting is growing continuously due to their greater energy efficiency, robustness, long life and light control. The possibly higher harmonic emission from these lamps has been mentioned however as a drawback. Not only is it important to know the individual harmonic emission of every device connected to the PCC, but it is also necessary to know the impact after the harmonic aggregation of those devices. In this paper, the harmonic emission of HPS lamps with electronic ballasts and LED street lamps has been studied. Different approaches on estimating the emission from multiple lamps are compared. The approach according to IEC 61000-3-6 has been compared with measurements, showing the limitations of that approach.
\end{abstract}

\section{INTRODUCTION}

The public lighting systems in our cities are a basic and vital service for city councils and other public administrations. On the one hand, citizens demand high quality service in accordance with our highly developed society. On the other hand, a lighting installation is an important energy consumer that is affected by factors such as regulation and maintenance.

To understand how a particular device contributes to the emission from the complete installation, the use of complex harmonic current (magnitude as well as phase angle) is needed. The harmonic emission should be studied through both magnitude and phase angle. The emission is normally quantified in terms of magnitude of the current harmonics as the magnitude distortion is what determines the impact on the grid and on other customers. However, the phase angle is also important especially for research and development purposes because it allows us to study and better understand any cancellation effects between devices and customers. Moreover, in a real system, distorting equipment can produce harmonics with strongly different phase angle. Another important fact is that some equipment does not operate simultaneously due to system or load constraints. One device in its own implies no problem, however, in street lighting many lamps are connected together and the total emission might be unacceptable. When estimating compliance to the limits for new or expanding facilities with multiple harmonic loads such as LED street lamps, the summation of harmonics from the loads has to be considered. Regarding to this aggregation, a distinction between primary and secondary emissions has been considered [1]. This paper examines existing harmonic summation methods defined in IEC 61000-3-6 [2] and illustrates the application of these methods based on measured data from various street lamps. Several street lamp combinations have been measured, by including those with same harmonic characteristics and those with different characteristics. Up to five HPS lamps connected to the same brand of electronic ballasts, and two different LED street lamps connected to the same PCC have been studied.

The different approaches on estimating harmonic emission from load aggregation have been considered through both the combination of equal loads (HPS lamps connected to electronic ballasts), and the combination of different loads (LED street lighting).

\section{METHODOLOGY}

Methods of combining multiple sources have been tested for LED street lights and HPS lamps connected to electronic ballasts. A linear combination gives the most pessimistic results of voltage distortion since it is assumed that the current injections from multiple sources are all in phase. A vector sum gives a more accurate result but requires information on the phase of the harmonics with respect to each other, which is not always available. A more generic law is recommended in IEC 61000-3-6 [2].

$$
M_{h}=\sqrt[\alpha]{\sum_{i} M_{h i}^{\alpha}}
$$

Where $M_{h}$ is either the voltage or current harmonic magnitude (order $h$ ) for the aggregated devices considered, $M_{h i}$ is the magnitude for the different individual levels (order $h$ ) that will be aggregated, and $\alpha$ is an exponent that depends on the harmonic order (see Table 1).

Table 1. Summation exponents for harmonics, according to IEC 61000-3-6 [2].

\begin{tabular}{|l|l|}
\hline \multicolumn{1}{|c|}{$\boldsymbol{\alpha}$} & \multicolumn{1}{c|}{ Harmonic Order } \\
\hline 1 & $\mathrm{~h}<5$ \\
\hline 1.4 & $5<\mathrm{h}<10$ \\
\hline 2 & $\mathrm{~h}>10$ \\
\hline $\begin{array}{l}\text { Note }- \text { When it is known that the harmonics are likely to } \\
\text { be in phase (i.e. phase angle difference less than } 90^{\circ} \text { ), } \\
\text { then an exponent } \alpha=1 \text { should be used for order } 5 \text { and } \\
\text { above. }\end{array}$ \\
\hline
\end{tabular}

All the above methods have been applied to LED street lights and HPS lamps connected to electronic ballasts. Regarding the measurement device used for the experiments, the current taken by the lamps was measured 
using both a Dranetz PowerGuide 4400 and a Power Explorer PX5 to obtain 30-second values for all the typical power quality parameters as well as a 200 ms waveform of the current every 30 seconds with a sampling frequency equal to $12.8 \mathrm{kS} / \mathrm{s}$. In order to have a stable current, the spectrum was measured over 4500 consecutive 30 -second intervals. This will allow us to characterize the harmonic emission because it is rather constant over these samples.

\section{RESULTS}

\section{Individual lamps}

The first group of lamps considered has been five identical HPS lamps Philips SON 70W/220 I E27 1CT [3] connected to an electronic ballast OSRAM Powertronic ${ }^{\circledR}$ PTo DALI 70/220-240 3DIM [4]. Usually the power loss of each electronic ballast is around $10 \mathrm{~W}$. For high frequency control, the lamps cannot be fully dimmed to extinction, and residual light output and power consumption will appear. However, such system operation may be less noticeable and less annoying to traffic participants. Ballasts are dimmable from $60 \%$ to $100 \%$ of the lamp input power, but the measurements presented here have been conducted for $100 \%$ of the arc power. More details about the energy efficient street lighting remote management system used in this experiment can be found in [5], [6]. The measured total harmonic distortion (THDI) at $100 \%$ of arc power level is $11.4 \%$, and the displacement power factor (DPF) at $100 \%$ of light output was measured to be 0.9745 , corresponding to $13^{\circ}$ shift between the fundamental waveforms of voltage and current. In the following figures only odd harmonics have been shown, because even harmonics are small over the whole frequency range.

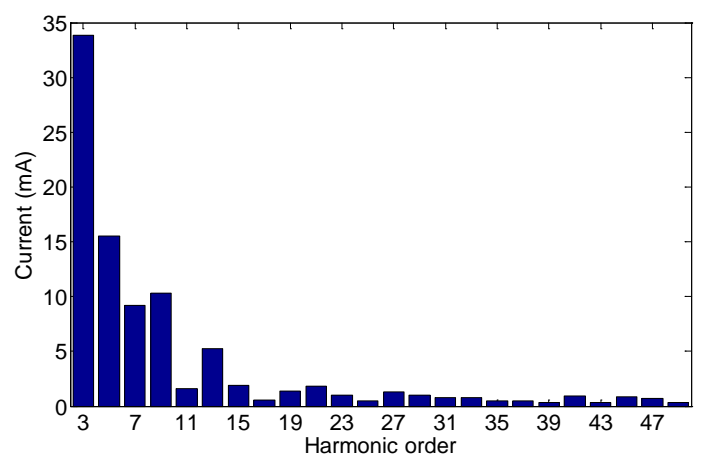

Figure 1. Harmonic current spectrum from a HPS lamp connected to electronic ballast set to $100 \%(\mathrm{~mA})$.

The highest magnitude is reached by the $3^{\text {rd }}$ harmonic, reaching $34 \mathrm{~mA}$ (9.6\% FND) for $100 \%$ of light output. This value is followed by the $5^{\text {th }}(15 \mathrm{~mA})$, then $7^{\text {th }}$ and $9^{\text {th }}$ harmonics which have a similar magnitude, around $9.8 \mathrm{~mA}$ (2.7\% of FND). The higher orders are around $1.2 \mathrm{~mA}(0.3 \%$ of FND).

The second group of lamps being studied is formed by two LED street lamps from different manufacturers.
Individually, they have the spectra shown in Fig. 2 and 3. The first LED street light monitored was a Thorn lamp, with an active power of $25 \mathrm{~W}$, and according to our measurements other values are 6.8\% THDI and a DPF of 0.96 .

The first conclusion to be drawn from this figure is that harmonics 3, 9, 13 and 15 are dominant. The rest odd harmonics have the same level. The fundamental of the current is $117 \mathrm{~mA}$. The $3^{\text {rd }}$ harmonic current is the highest in magnitude, but it is relatively low if we compare it with other light technology, only $6.5 \mathrm{~mA}$ (5.4\% FND). The other orders are around $1 \mathrm{~mA}(1 \% \mathrm{FND})$. The $9^{\text {th }}, 13^{\text {th }}$ and $15^{\text {th }}$ harmonic are also higher than the frequencies around them. They are $2.85 \mathrm{~mA}$ (2.5\% FND), $1.8 \mathrm{~mA}$ (1.6\% FND), and $1.5 \mathrm{~mA}$ (1.25\% FND) respectively.

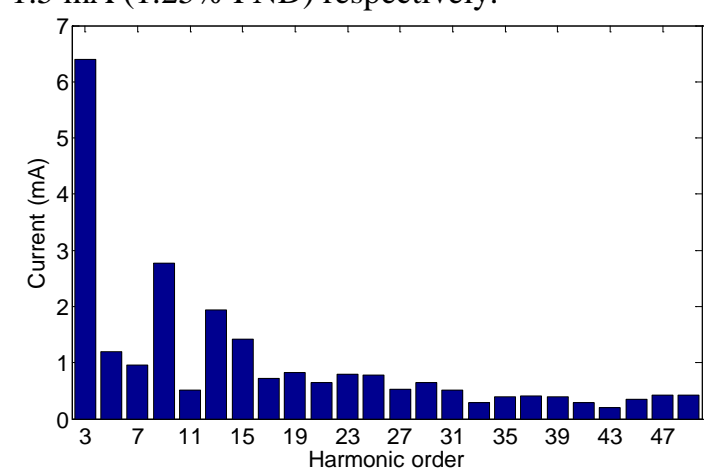

Figure 2. Harmonic current spectrum from a LED street light lamp $(m A)$.

Another LED lamp with high power was also recorded and analysed. The luminaire was a matrix of 30 LEDs, and the LED driver belongs to UE Electronic. Some data are THDI $18.16 \%$ and a DPF of 0.961 . In this case, the fundamental of the current is $188 \mathrm{~mA}$. The current harmonic emission from this second LED street lamp is shown in Fig. 3. All the harmonic orders show higher magnitudes than in the previous LED lamp, in absolute value as well as in percent of the nominal current. Whereas in Fig. 2 appears the $3^{\text {rd }}$ order with a magnitude of $6.5 \mathrm{~mA}$; in this case is around 28 $\mathrm{mA}\left(15 \%\right.$ of the FND); the same with $5^{\text {th }}$ and $7^{\text {th }}$, which in the previous lamp were $1 \mathrm{~mA}$, and now it is $15 \mathrm{~mA}$ (7\% and $4 \%$ of FND respectively). Generally, it can be seen that the spectra of both LED street lamps are very much different.

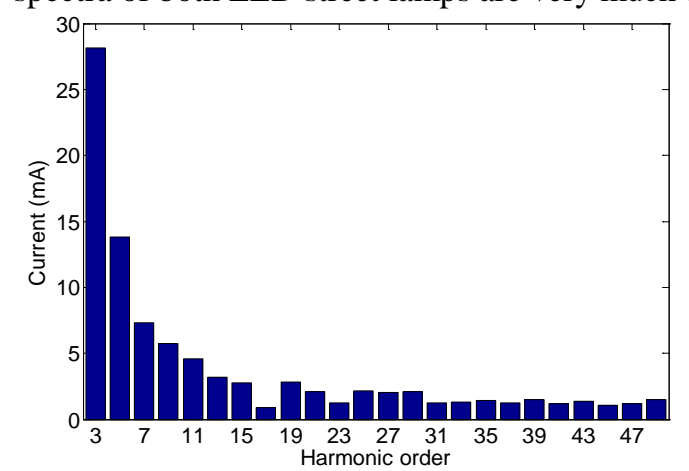

Figure 3. Harmonic current spectrum from another LED street light $\operatorname{lamp}(m A)$. 
In spite of those comments, overall the harmonic emission corresponds, as the previous LED lamp, with a broadband spectrum, with a relatively high $3^{\text {rd }}$ current harmonic, a decreasing tendency from this order up to $15^{\text {th }}$, followed by stabilization around $2.5 \mathrm{~mA}$. The emission has a minimum for harmonics 17 and 23. There is no specific reason for this, but a common feature of diode rectifiers [7].

\section{Experimental Aggregation}

In order to study the harmonic spectrum resulting from the addition of different number of street lamps, not only the magnitude but also the phase angle information is needed. The presentation of the harmonic current in the complex plane provides a suitable way for a graphical analysis of the summation effects for the individual harmonics. The magnitude of the complex harmonic current is the magnitude as obtained from the DFT (discrete Fourier transform) over the waveform current; the argument is the phase angle calculated as described in IEC 61000-3-12 [8]. Starting with the addition of up to five equal sodium lamps connected to electronic ballasts (individual emission shown in Fig. 1), complex current in the complex plane for $3^{\text {rd }}, 5^{\text {th }}$, $7^{\text {th }}$ and $9^{\text {th }}$ harmonics has been calculated and the average is shown in Fig. 4.

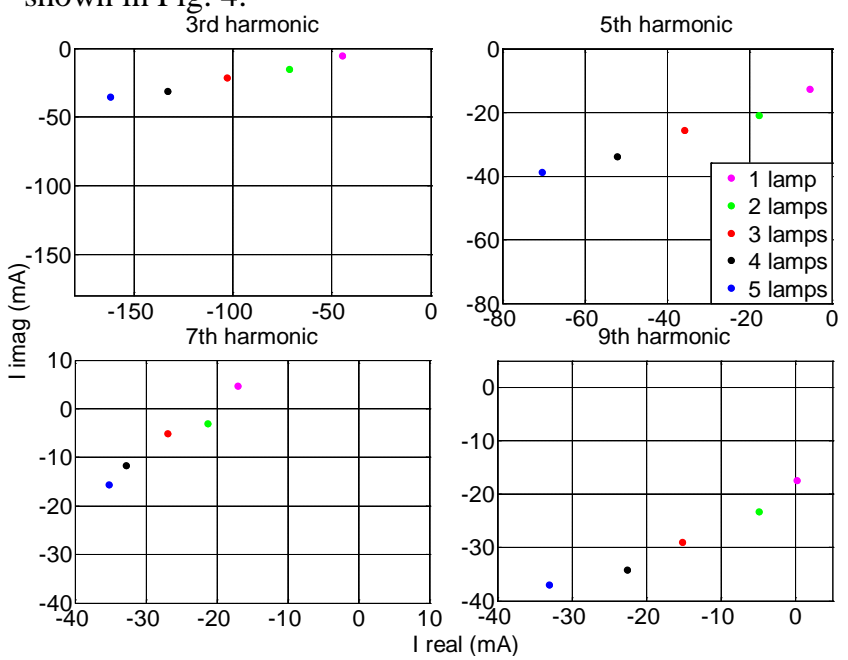

Figure 4. Complex harmonic current after the addition of sodium street lamps.

To understand these results a distinction has to be made between primary emission [1] (the part of the current driven by the internal emission of the device itself) and secondary emission [1] (current flowing at the interface between a device and the grid due to a disturbance source elsewhere). When measuring at the PoC, results show the primary emission from one to five lamps, together with the secondary emission of 5 electronic ballasts (they were always connected, although the lamps were switching on one by one). As shown in the figure, the more lamps are connected, the higher the current harmonic in magnitude. Moreover, the emission from one lamp is slightly higher compared with the individual emission shown in Fig. 1, due to the secondary emission. The latter cannot be neglected.
Then, it will be studied the aggregation of two different LED street lamps (their corresponding individual emissions appear in Fig. 2, 3). Both the individual and the aggregated complex harmonic currents are in Fig. 5 and 6.

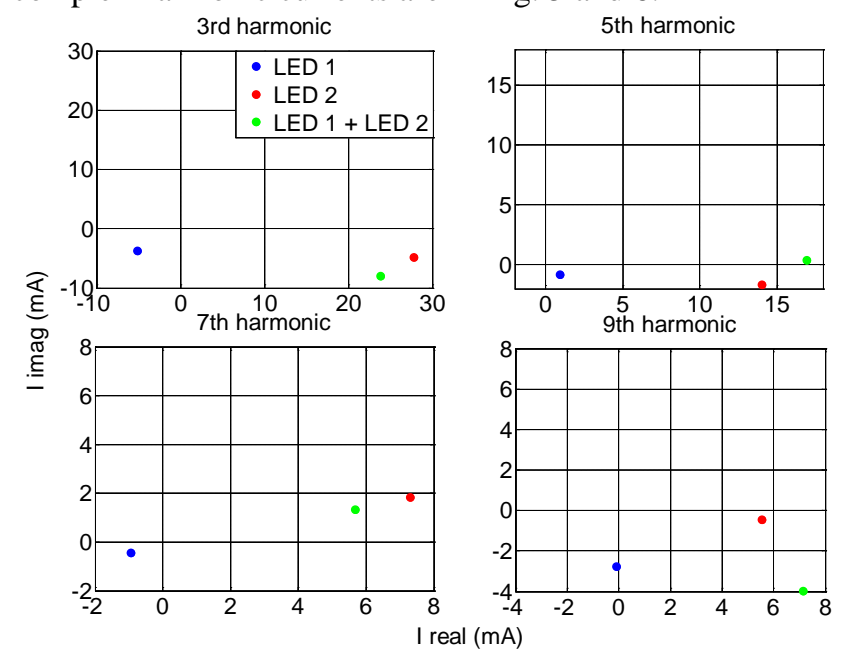

Figure 5. Complex harmonic current from one and two LED street lamps.

In this case, because all the complex currents belong to different quadrants, therefore having different phase angles, the combination does result in a decrease in the resultant current harmonic magnitude. The latter can also be seen if we only plot their corresponding magnitudes.

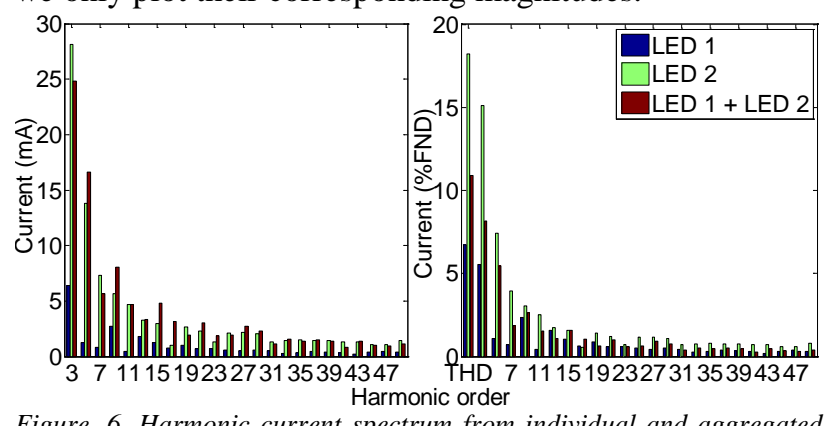

Figure. 6. Harmonic current spectrum from individual and aggregated LED street lamps.

Due to the diversity, the harmonic emission of two LED lamps connected to the same PCC is lower than even one of them individually.

\section{Estimated Aggregation}

The harmonic emission from combined loads is indicated in IEC 61000-3-6 [2] by the summation exponent, where it is considered the angle diversity. The different approaches on estimating harmonic emission after load aggregation have been considered with equal loads (HPS lamps connected to electronic ballasts), and with different loads (LED street lighting).

Under the 'IEC model' the summation exponent indicated in IEC 61000-3-6 has been considered. In the 'adding waveforms' approach, the waveforms from the five individual lamps have been added, and then, the harmonic emission has been calculated. Finally, 'measurement' 
contains the result from connecting together all the five lamps.

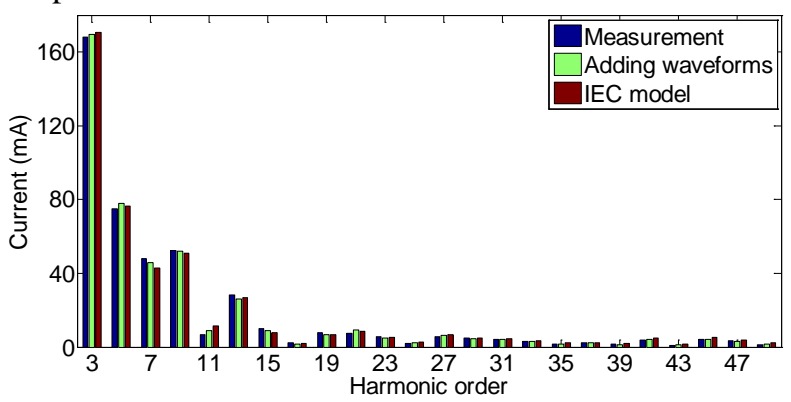

Figure 7. Harmonic current spectrum from 5 aggregated sodium street lamps.

For most harmonics there is a reasonable agreement between the three methods; this is especially the case for the dominant harmonics (3, 5, 7, 9 and 13).However, the results are different when combining LED street lamps from different manufactures. Under the 'IEC model' the summation exponent indicated in IEC 61000-3-6 (shown in Table 1) has been considered. In the 'adding waveforms' approach, the waveforms from the two individual lamps have been added, and then, the harmonic emission has been calculated. Only the magnitudes from each lamp have been added without considering the diversity effect in the 'adding magnitudes'. Finally, 'measurement' contains the result from connecting together both lamps.

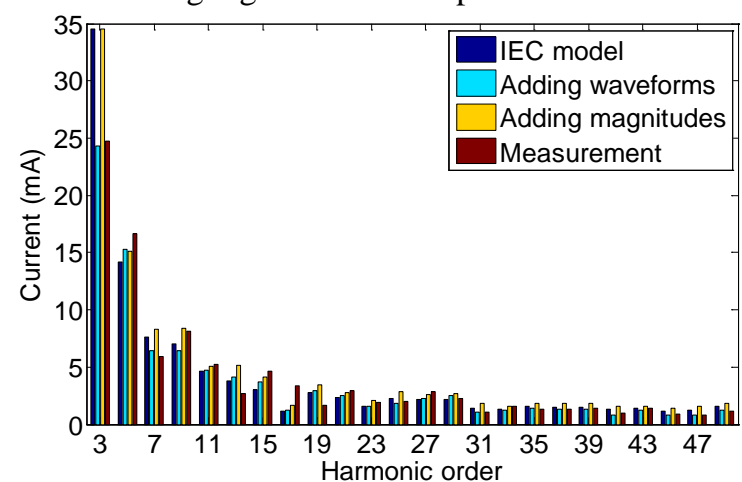

Figure 8. Different approaches on estimating harmonic emission from 2 different LED street lamps.

The figure shows that the results obtained by using the summation exponents are often different from the results obtained through measurements. The IEC model gives an overestimation for most harmonics (for higher harmonics the absolute error may be small, but the result from the IEC approach is often twice as high as the result from the experimental approach). In fact, the lower the harmonic order, the higher the difference. There is no general trend visible $_{2}$ which confirms that measurements are needed and/or that an alternative for the IEC aggregation model is needed for electrical installations.

The result obtained by adding the waveform from individual lamps is closer to the measurement results but there are still relatively large differences in some cases.

\section{CONCLUSIONS}

From the study with HPS lamps connected to electronic ballasts, it can be concluded that there is only limited cancellation between individual lamps from the same manufacturer up to five measured lamps. In LED street lamps from different manufacturers there is cancellation due to differences in phase angles among the lamps. Adding the magnitude spectra (low and high order harmonics) from individual devices can greatly overestimate the emission from an installation with mixed load. The summation exponent from IEC 61000-3-6 gives results often different from measurements.

\section{Acknowledgments}

The authors would like to thank the Spanish Ministry of Industry, Tourism and Trade for funding the Project TSI020100-2010-484 which partially supports this work. Our unforgettable thanks to the Spanish Ministry of Science and Innovation for funding the research project TEC201019242-C03-02. Part of this work has been supported financially by Skellefteå Kraft, and the Swedish Energy Administration.

\section{REFERENCES}

[1] S. Rönnberg, M. Bollen, and A. Larsson, "A simple model for interaction between equipment at a frequency of come tens to $\mathrm{kHz}, "$ in Electricity Distribution - Part 1, 2011. CIRED 2011. 21st International Conference and Exhibition on, 2011, pp. $1-4$.

[2] W. R. Ryckaert, K. A. G. Smet, I. A. A. Roelandts, M. Van Gils, and P. Hanselaer, "Linear LED tubes versus fluorescent lamps: An evaluation," Energy and Buildings, vol. 49, pp. 429-436, 2012.

[3] Philips Lighting. Available: http://www.lighting.philips.com

[4] OSRAM. Available: http://www.osram.com

[5] F. Domingo-Perez, A. Gil-de-Castro, J. M. FloresArias, F. J. Bellido-Outeirino, and A. Moreno-Munoz, "Low-rate wireless personal area networks applied to street lighting," Lighting Research and Technology, Prepublished December 14, 20112011.

[6] A. Gil-de-Castro, A. Moreno-Munoz, A. Larsson, J. J. G. de la Rosa, and M. H. J. Bollen, "LED Street lighting: A power quality comparison among street light technologies," Lighting Research and Technology, first published on August 7, 20122012.

[7] M. H. J. Bollen and I. Y. H. Gu, Signal processing of power quality disturbances: IEEE Press, 2006.

[8] "Electromagnetic compatibility (EMC) - Part 3-12: Limits - Limits for harmonic currents produced by equipment connected to public low-voltage systems with input current $>16 \mathrm{~A}$ and $\leq 75 \mathrm{~A}$ per phase, IEC 61000-3-12 ed2.0 ", May 2011. 